\title{
Not All Are Equal: A Latent Profile Analysis of Well-Being Among the Self-Employed
}

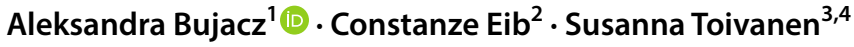 \\ Published online: 12 July 2019 \\ (c) The Author(s) 2019
}

\begin{abstract}
This study uses a person-centered approach to distinguish between subpopulations of selfemployed individuals using multidimensional well-being indicators. Data were obtained from European Social Survey including a sample of 3461 self-employed individuals from 29 European countries. The analysis has empirically identified six distinct profiles named 'unhappy', 'languishing', 'happy', 'satisfied', 'passionate', and 'flourishing'. The profiles were associated with significant differences in well-being, health and work-related variables. The results highlight the heterogeneity of the self-employed population, and describe the complex-both hedonic and eudaimonic-character of the well-being concept in this population.
\end{abstract}

Keywords Well-being · Self-employment · Person-centered $\cdot$ Latent profile analysis

Thus far, little attention has been given to the heterogeneity among the self-employed in terms of their well-being. In general, the self-employed report high levels of well-being (Baron et al. 2016; Stephan and Roesler 2010; Uy et al. 2013). However, the positive relationship between self-employment and well-being may be limited to the rich (Alesina et al. 2001), to the younger and highly educated (Rietveld et al. 2015), to those who became self-employed out of opportunity rather than necessity (van der Zwan et al. 2016), to selfemployed with employees and to immigrant self-employed (Johansson Sevä et al. 2016).

Electronic supplementary material The online version of this article (https://doi.org/10.1007/s1090 2-019-00147-1) contains supplementary material, which is available to authorized users.

Aleksandra Bujacz

aleksandra.bujacz@ki.se

Constanze Eib

constanze.eib@psyk.uu.se

1 Division of Psychology, Department of Clinical Neuroscience, Karolinska Institutet, Tomtebodavägen 18a, 17177 Stockholm, Sweden

2 Department of Psychology, Uppsala University, Von Kraemers allé 1A och 1C, 75237 Uppsala, Sweden

3 Academy of Health, Care and Social Welfare, Mälardalen University, Västerås, Sweden

4 Department of Public Health Sciences, Stockholm University, Stockholm, Sweden 
Moreover, most research has adopted a narrow view of well-being, investigating the effects of self-employment only on life satisfaction or job satisfaction and ignoring other important well-being indicators (Benz and Frey 2008; Lange 2012). Keeping in mind both the heterogeneity of the self-employed population and the complexity of the well-being concept, it is unlikely that all enjoy unanimously high levels of well-being. Thus, it seems crucial to identify and quantify to what extent and in which aspects well-being may vary within the self-employed group.

This study identifies profiles of the self-employed taking into account different wellbeing indicators. Such approach relaxes the assumption that all individuals in the sample belong to the same population (Morin et al. 2018; Wang and Hanges 2011), and thus it is especially appropriate for a study that aims at exploring how individuals differ from one another. By estimating profiles, we investigate a more comprehensive well-being concept than it was previously studied among the self-employed. Moreover, we use several health and work-related variables to explain the profile membership. Thus, the unique contribution of this study lays in systematically identifying and comparing specific groups of the self-employed both in terms of the amount and the type of their well-being.

\section{Identifying the Well-Being Profiles}

Although there are many debates on what constitutes a 'good life', scholars agree that wellbeing is a complex and multidimensional concept. A popular distinction is the one between hedonic and eudaimonic well-being (Bujacz et al. 2014; Huta and Waterman 2014). Hedonic well-being is often the prevailing approach to well-being measurement, usually meaning that only life satisfaction is assessed, sometimes in addition to the presence of positive affect and the absence of negative affect (Kashdan et al. 2008). This is also true for much of the studies on well-being of the self-employed. Thus, little is known about the amount and distribution of eudaimonic aspects of well-being in this group.

The eudaimonic approach has recently gained significant attention from well-being researchers (Huta and Waterman 2014). It points out that pleasant feelings and favorable evaluations are not enough and well-being aspects related to positive functioning in life should also be considered (Vitters $\varnothing$ and Dahl 2013). These include, for example, having a meaningful life, being interested and engaged, and fulfilling one's potential and aspirations. In fact, current findings suggest that pursuing both hedonic and eudaimonic wellbeing may be the most beneficial for individuals (Huta and Ryan 2010). Thus, the selfemployment literature may also advance from simultaneously investigating hedonic and eudaimonic aspects of well-being.

A downside of the multidimensional approach to defining well-being is that no consensus seems to exist about the number and kinds of core well-being dimensions. Different scholars have made lists of such dimensions including from three to over ten indicators (Deci and Ryan 2000; Huppert and So 2013; Ryff 2013; Schueller and Seligman 2010). Therefore, in this study we base our selection of well-being indicators on two main criteria. First, indicators should reflect a job-related well-being when applied to the self-employed. Second, the indicators should represent both hedonic and eudaimonic well-being.

Given these considerations, we assessed the hedonic aspect of well-being with two indicators capturing work-related evaluations: job satisfaction and satisfaction with worklife balance. Job satisfaction can be defined as an evaluative judgment of one's job (Weiss 2002), which has been consistently shown to be higher among self-employed than among 
employed individuals (Benz and Frey 2008; Bradley and Roberts 2004; Lange 2012). The issue of work-life balance satisfaction is also crucial for the well-being of self-employed workers, as they often have blurred boundaries between their work life and their private life (Myrie and Daly 2009). One motive to becoming self-employed can be the wish to balance work and life better and use the flexibility innate to being self-employed. However, being self-employed often brings about long work hours, financial risks and stressful work demands (Ezzedeen and Zikic 2017).

To assess the eudaimonic part of the well-being concept, we included four indicators of positive functioning: stress resistance, meaning, autonomy, and interest. These indicators reflect personal qualities that make it more likely for individuals to fulfill their needs and important life goals (Binder and Coad 2013). Stress resistance refers to the ability to adapt and recover from difficult challenges (Smith et al. 2010). Because of the level and variety of work stressors for self-employed, coping is an important area of research for this group (Uy et al. 2013). Meaning describes whether individuals see that their current activities are purposeful and lead to positive future states (Steger et al. 2009). Autonomy is often mentioned as the main reason for becoming self-employed (Schonfeld and Mazzola 2015). However, unlimited autonomy may also bring challenges to the self-employed, such as threats for autonomy by stakeholders (van Gelderen 2016). Finally, interest is an important indicator of engagement, which facilitates being actively involved and motivated to challenging life goals, learning new skills, and developing potentials (Vitters $\varnothing$ et al. 2009b). It is assumed that self-employed are highly engaged with their work, with some scholars characterizing repeated entrepreneurship as 'addiction' (Spivack et al. 2014). Similarly, passion of entrepreneurs is linked to both engagement and workaholism (Gorgievski et al. 2014). Thus, interest levels seem to be one of the crucial indicators of positive functioning among the self-employed.

In sum, the six indicators chosen to represent well-being of the self-employed may form various well-being profiles. This study is the first that uses person-centered approach to describe well-being among the self-employed, and one of the few that applied this methodology to study well-being in other populations (Bhullar et al. 2014; Chevalier et al. 2018; Heilala et al. 2014). Thus, we do not make any assumptions about which profiles of wellbeing among self-employed exist and at which prevalence. Instead, we adopt an exploratory approach with an aim to find which well-being profiles are typical for the self-employed.

Research Question 1 Which profiles of well-being can be distinguished among selfemployed and how prevalent are these profiles?

\section{Explaining the Well-Being Profiles}

Profiles of well-being are likely associated with demographic and work-related characteristics. This means that some characteristics may make it more likely for an individual to develop a certain well-being profile. For example, it is argued that older entrepreneurs know their strengths and weaknesses better and have better regulatory strategies to deal with negative events and derive meaning from them (Baron et al. 2016). Gender may also play a role in differentiating between profiles. The long working hours of the self-employed may negatively affect well-being of women more than men, as the former tend to carry the main responsibility for household and childcare (Parasuraman and Simmers 2001). Also, women tend to have more difficulties switching off from work (Sonnentag and Bayer 
2005). There are small differences in the motives of becoming self-employed between men and women, with women more likely to want to gain more flexibility and autonomy (Hilbrecht and Lero 2014; Stephan et al. 2015). However, it was also shown that self-employed women report worse health than similar employed women (Parslow et al. 2004). Thus, age and gender were both included as control variables in this study.

Self-employed workers may be more likely to have a certain well-being profile depending on their education, occupation, current income level, and on whether they have employees. Higher education, and thus a high-skilled work, is positively related to better health and well-being (Eurofound 2014). Higher education may also shape the motives for entering self-employment, as well as affect the type of business being managed (Stephan et al. 2015). Thus, there are differences in the health of self-employed across different sectors (Toivanen et al. 2015). The psychological situation for the self-employed differs also depending on whether they have employees or not (Rauch and Frese 2000). Most self-employed are sole proprietors and very few have more than five employees (Johansson Sevä et al. 2016). It was found that mortality rates are higher among sole proprietors (Toivanen et al. 2015), and self-employed without employees reported higher levels of job dissatisfaction, fatigue and muscular pain compared to self-employed with employees (Benavides 2000).

Finally, insufficient income is likely to be related to lower levels of life and work evaluations (Kahneman and Deaton 2010). Importantly, insufficient income refers to a subjective perception of one's earnings, which may be quite independent from the actual income level. For instance, while it was shown that female founders earned less than male founders, they were also more satisfied with their income (Carree and Verheul 2012). Another aspect is whether the income of the self-employed individual constitutes the main income source of the household. The responsibility of being the breadwinner may potentially be a stressor and provide a risk factor for lower well-being. In sum, there are reasons to believe that well-being profiles are linked to both individual and work-related characteristics.

Research Question 2 Are certain groups of self-employed (high-skilled individuals, employers, low income individuals) more likely to have a specific well-being profile?

\section{Validating the Well-Being Profiles}

One way to better understand empirically determined profiles of well-being among selfemployed is to relate the profiles to relevant external variables (Bergman et al. 2003). In this study, we include two types of such auxiliary variables: health-related and work-related.

In terms of health-related characteristics, we look at differences across the profiles regarding life satisfaction, overall happiness, self-rated health, depression and anxiety. Life satisfaction refers to a global assessment of satisfaction with one's life (Diener et al. 1985), and happiness refers to general assessment of positive emotions one experiences in life (Kahneman 2000). Both function as summative assessments of positive mental health from the hedonic perspective. However, previous studies suggest that general life evaluations do not relate to positive functioning indicators (Vitters $\emptyset$ et al. 2009a). Therefore, profiles with higher eudaimonic well-being indicators may not necessarily have higher life satisfaction or happiness scores. At the same time, profiles with higher work satisfaction scores should result in higher general life satisfaction. Due to this distinction, the general 
satisfaction scores are good validation variables that confirm the meaning of the empirically determined profiles.

An inclusion of health-related variables in this study may help determine to what extent certain well-being profiles are accompanied by an increased risk for health problems. Recently, the relevance of health has become acknowledged in the self-employment literature, noting that the health of the entrepreneur is vital to sustaining successful businesses (Uy et al. 2017). Self-rated health is an independent predictor of mortality, a relevant predictor for a wide range of health-related symptoms, and a good indicator for actual health (Idler and Benyamini 1997). We also compare the profiles on ill-being aspects: depression and anxiety. Depression reflects an overall negative orientation that facilitates negative emotional experiences (Insel and Charney 2003). Depressive symptoms hinder effective decision-making, such as opportunity recognition and uptake (Bradley and Roberts 2004). Together with depression, anxiety is the second most common mental disorder, with symptoms including worrying, an inability to concentrate and relax, as well as physical discomfort (Barlow 2000). Both are most likely negatively related to business success (Gorgievski et al. 2014; Rietveld et al. 2015).

In terms of work-related characteristics, individuals with different well-being profiles may also differ in their work hours, socioeconomic position and income. Although work demands are generally negatively related to health and well-being, research suggests that work hours and well-being stand in a complex relationship, such that some individuals manage to stay happy and healthy while working long hours (Akerstedt et al. 2002). It is also interesting to see whether differences in income follow different well-being profiles, especially because self-employed individuals have been reported to earn less than comparable employees (Andersson 2008). However, research suggests that the return on wellbeing with increased level of income is limited (Clark et al. 2008; Kahneman et al. 2006). In general, individuals in profiles characterized by high-income levels may be expected to also have higher socioeconomic position and life satisfaction.

In sum, to interpret and explain the unique empirical profiles of well-being among the self-employed, this analysis will compare the profiles on different variables related to both work and health aspects.

Research Question 3 How do profiles of well-being differ in terms of health-related and work-related variables?

\section{Method}

\subsection{Participants}

The study was based on the data collected during the European Social Survey Round 6 (European Social Survey 2012). The current analysis included a subsample of participants $(N=3461 ; 32.9 \%$ women; mean age $=47.12$, ranging from 18 to 89 years $)$ from 29 European countries. Selected participants fulfilled the following inclusion criteria: (a) were working, (b) were self-employed, and (c) have answered to all questions selected as wellbeing indicators. The last inclusion criterion resulted in excluding 73 participants. The number of participants and the percentage of the entire sample included in the analysis in each of the countries are presented in the Supplementary Material. 


\subsection{Measures}

Measures included in the analysis were divided into three categories. First, we chose six indicators that formed the well-being profiles: job satisfaction, work-life balance satisfaction, interest, stress resistance, meaning, and autonomy. Second, we identified five covariates that helped understand who is more likely to hold a certain well-being profile: education, being an employer, occupation, main income source, and insufficiently low income. Finally, we described eight characteristics associated with profile membership. Three of them were work-related (income, subjective socioeconomic position, and work hours) and five were health-related (self-rated health, life satisfaction, general happiness, depression, and anxiety). Exact wording and response scales for all the measures are presented in the Supplementary Material.

\section{Analyses}

Due to sizeable differences in mean scores of indicators and covariates at the country level, all continuous variables measured as self-reported ratings were country-mean centered. Variables with scales including a meaningful zero (i.e., age and work hours) were grandmean centered. Standard scores were used in all plots as they provide a common scale for the indicators and are more easily interpreted (Meyer and Morin 2016).

The data were analyzed using Latent Profile Analysis, a modelling approach in which the latent variable is categorical and the indicators are treated as continuous (Collins and Lanza 2010). A latent categorical variable represents multiple subpopulations characterized by different levels of indicators (Wang and Hanges 2011). Thus, this analytical strategy allows for empirical distinction of fairly homogenous groups of people within the sample, and unlike traditional clustering approaches it takes into account the goodness-of-fit of the model and the measurement error (Morin 2016). Thus, the best fitting model is chosen based on the variety of statistical indicators as well as the substantive meaning of the solution (Marsh et al. 2009).

Covariates were included into the model following the three-step approach (Asparouhov and Muthén 2014). The effects of the covariates were compared by testing whether each of the covariates contributes to the classification above and beyond other covariates (Collins and Lanza 2010). For model comparisons, the BIC difference was used. A difference value higher than 10 provides strong evidence against the model with the higher BIC value (Kass and Raftery 1995). We tested the significance of mean-level differences in healthrelated and work-related characteristics across all specific pairs of profiles using the $\mathrm{BCH}$ approach (Bakk and Vermunt 2016).

\section{Results}

The choice of the six-profile solution was based on the information criteria and the meaningfulness of the obtained solution (see the Supplementary Material). The information criteria kept improving with the addition of latent profiles, yet the decreases in 
Table 1 Mean levels and variances of well-being indicators in the retained latent profile model $(\mathrm{N}=3461)$

\begin{tabular}{llllllllllllll}
\hline & $\begin{array}{l}\text { Unhappy } \\
(15.2 \%)\end{array}$ & \multicolumn{3}{l}{$\begin{array}{l}\text { Languishing } \\
(34.2 \%)\end{array}$} & $\begin{array}{l}\text { Happy } \\
(22.9 \%)\end{array}$ & \multicolumn{2}{l}{$\begin{array}{l}\text { Satisfied } \\
(6.3 \%)\end{array}$} & \multicolumn{2}{l}{$\begin{array}{l}\text { Passionate } \\
(11.8 \%)\end{array}$} & \multicolumn{3}{l}{$\begin{array}{l}\text { Flourish- } \\
\text { ing }(9.6 \%)\end{array}$} \\
\hline Job sat. & -2.38 & 5.09 & -0.39 & 1.58 & 0.68 & 0.80 & 1.77 & 0.58 & 0.45 & 2.83 & 1.87 & 0.32 \\
Work-life & -2.32 & 5.21 & -0.67 & 2.79 & 1.21 & 1.07 & 2.66 & 0.68 & -1.02 & 5.15 & 2.67 & 0.60 \\
Interest & -1.50 & 4.45 & -0.53 & 1.47 & 0.30 & 0.86 & -0.09 & 2.93 & 1.55 & 0.27 & 1.68 & 0.28 \\
Stress resistance & -1.29 & 3.99 & -0.35 & 2.18 & 0.81 & 1.14 & -0.73 & 6.45 & 0.44 & 4.19 & 1.39 & 2.51 \\
Meaning & -1.89 & 5.35 & -0.45 & 1.60 & 0.59 & 1.10 & -0.56 & 5.64 & 1.45 & 0.90 & 1.76 & 0.64 \\
Autonomy & -1.68 & 5.79 & -0.71 & 3.38 & 1.12 & 1.44 & 0.23 & 5.37 & 0.05 & 7.31 & 2.31 & 1.42 \\
\hline
\end{tabular}

Variances are presented in italics. Values in percentage represent final class proportions based on the estimated model. Indicators are estimated from country-mean centered variables

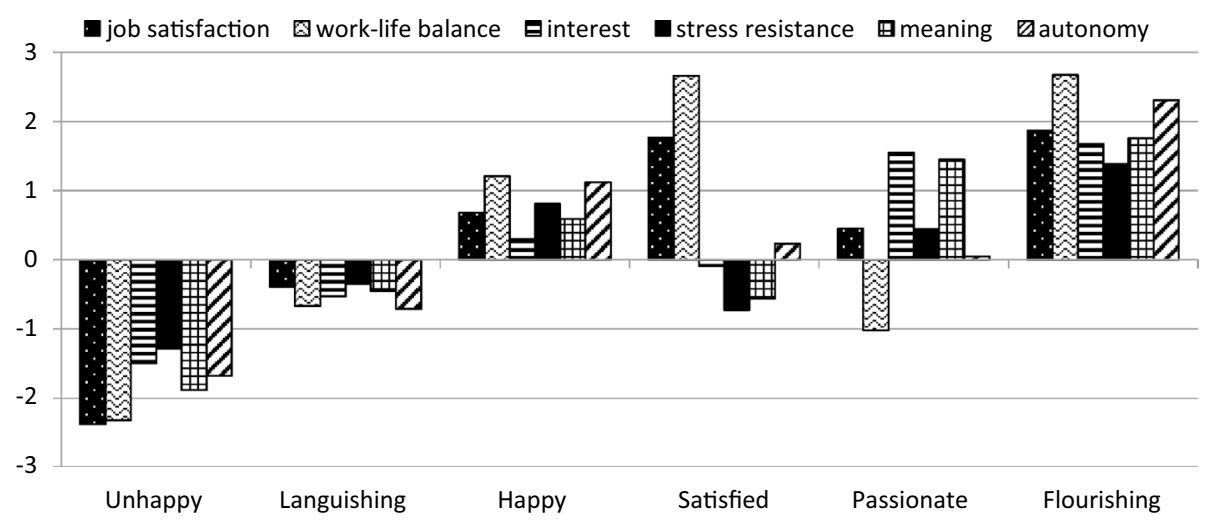

Fig. 1 Mean levels of well-being indicators in the retained latent profile model. Note Indicators are estimated from country-mean centered variables

BIC values reached a plateau around 5-6 profiles. The six-profile solution included not only profiles characterized by low or high levels of all indicators, but also two profiles characterized by different levels of work evaluations and functioning well-being indicators. Thus, we decided that the six-profile solution provides the most detailed and meaningful description of the sample of self-employed workers analyzed in this study. Table 1 and Fig. 1 present mean levels of well-being indicators in the retained latent profile model.

All the covariates were shown to significantly contribute to the classification above and beyond each other (education $\triangle \mathrm{BIC}=32$, being an employer $\triangle \mathrm{BIC}=350$, high-skilled occupation $\triangle \mathrm{BIC}=104$, self-employment as the main income source $\Delta \mathrm{BIC}=178$, and subjectively low income $\Delta \mathrm{BIC}=222$ ). Gender and age were also included in the model, yet they did not contribute above and beyond other covariates. Table 2 presents the results of the multinomial logistic regressions, in which each covariate has five complementary effects for each possible pairwise comparison of profiles. For clarity of interpretation, in the Table 2 we also report odds ratios (OR) reflecting the change in the likelihood of membership in a target profile versus a comparison profile.

Finally, all health-related and work-related characteristics were shown to significantly differ across profiles (all $p<0.001$ ). Table 3, Figs. 2, and 3 illustrate differences between 
Table 2 Logistic regression results evaluating the effects of covariates on latent profile membership

\begin{tabular}{|c|c|c|c|c|c|c|c|c|c|c|c|c|}
\hline \multirow[b]{2}{*}{ Unhappy (1) } & \multicolumn{2}{|l|}{ vs. (1) } & \multicolumn{2}{|l|}{ vs. (2) } & \multicolumn{2}{|l|}{ vs. (3) } & \multicolumn{2}{|l|}{ vs. (4) } & \multicolumn{2}{|l|}{ vs. (5) } & \multicolumn{2}{|l|}{ vs. (6) } \\
\hline & & & & & & & & & & & & \\
\hline Education & - & & -0.21 & 0.81 & $-\underline{0.32}$ & $\underline{0.73}$ & 0.09 & 1.10 & -0.21 & 0.81 & -0.47 & 0.62 \\
\hline Employer & - & & -0.11 & 0.90 & 0.19 & 1.21 & 0.08 & 1.09 & $-\underline{0.33}$ & $\underline{0.72}$ & 0.19 & 1.21 \\
\hline Occupation & - & & 0.04 & 1.04 & -0.37 & 0.69 & 0.17 & 1.19 & -0.02 & 0.98 & -0.30 & 0.74 \\
\hline Income source & - & & 0.20 & 1.22 & 0.22 & 1.25 & -0.41 & $\underline{0.66}$ & 0.28 & 1.32 & 0.04 & 1.04 \\
\hline Low income & - & & 1.41 & 4.12 & 2.85 & 17.3 & 1.16 & 3.19 & 0.84 & 2.31 & 2.24 & 9.36 \\
\hline \multicolumn{13}{|l|}{ Languishing (2) } \\
\hline Education & 0.21 & 1.23 & - & & -0.11 & 0.90 & 0.30 & 1.35 & 0.00 & 1.00 & -0.26 & 0.77 \\
\hline Employer & 0.11 & 1.11 & - & & 0.30 & 1.35 & 0.19 & 1.21 & -0.23 & 0.80 & $\underline{0.30}$ & 1.34 \\
\hline Occupation & -0.04 & 0.96 & - & & -0.41 & 0.66 & 0.13 & 1.14 & -0.06 & 0.94 & -0.34 & $\underline{0.71}$ \\
\hline Income source & -0.20 & 0.82 & - & & 0.03 & 1.03 & -0.61 & 0.54 & 0.08 & 1.08 & -0.16 & 0.85 \\
\hline Low income & -1.41 & 0.24 & - & & 1.43 & 4.20 & -0.25 & 0.78 & -0.58 & 0.56 & 0.82 & 2.27 \\
\hline \multicolumn{13}{|l|}{ Happy (3) } \\
\hline Education & $\underline{0.32}$ & $\underline{1.37}$ & 0.11 & 1.11 & - & & 0.41 & 1.51 & 0.11 & 1.11 & -0.15 & 0.86 \\
\hline Employer & -0.19 & 0.82 & -0.30 & 0.74 & - & & -0.11 & 0.90 & -0.52 & 0.59 & -0.01 & 0.99 \\
\hline Occupation & 0.37 & 1.44 & 0.41 & 1.50 & - & & 0.54 & 1.71 & $\underline{0.35}$ & $\underline{1.42}$ & 0.07 & 1.07 \\
\hline Income source & -0.22 & 0.80 & -0.03 & 0.97 & - & & -0.64 & 0.53 & 0.05 & 1.06 & -0.19 & 0.83 \\
\hline Low income & -2.85 & 0.06 & -1.43 & 0.24 & - & & -1.67 & 0.18 & -2.01 & 0.13 & -0.61 & 0.54 \\
\hline \multicolumn{13}{|l|}{ Satisfied (4) } \\
\hline Education & -0.09 & 0.91 & -0.30 & 0.74 & -0.41 & 0.66 & - & & -0.30 & 0.74 & -0.56 & 0.57 \\
\hline Employer & -0.08 & 0.92 & -0.19 & 0.83 & 0.11 & 1.11 & - & & $-\underline{0.41}$ & $\underline{0.66}$ & 0.11 & 1.11 \\
\hline Occupation & -0.17 & 0.84 & -0.13 & 0.88 & -0.54 & 0.58 & - & & -0.19 & 0.83 & $-\underline{0.47}$ & $\underline{0.63}$ \\
\hline Income source & $\underline{0.41}$ & $\underline{1.51}$ & 0.61 & 1.84 & 0.64 & 1.89 & - & & 0.69 & 2.00 & $\underline{0.45}$ & 1.56 \\
\hline Low income & -1.16 & 0.31 & 0.25 & 1.29 & 1.67 & 5.41 & - & & -0.33 & 0.72 & 1.07 & 2.23 \\
\hline \multicolumn{13}{|l|}{ Passionate (5) } \\
\hline Education & 0.21 & 1.23 & 0.00 & 1.00 & -0.11 & 0.90 & 0.30 & 1.35 & - & & -0.26 & 0.77 \\
\hline Employer & $\underline{0.33}$ & $\underline{1.39}$ & 0.23 & 1.25 & 0.52 & 1.69 & $\underline{0.41}$ & $\underline{1.51}$ & - & & 0.52 & 1.69 \\
\hline Occupation & 0.02 & 1.02 & 0.06 & 1.06 & $-\underline{0.35}$ & $\underline{0.70}$ & 0.19 & 1.21 & - & & -0.28 & 0.75 \\
\hline Income source & -0.28 & 0.76 & -0.08 & 0.92 & -0.05 & 0.95 & -0.69 & 0.50 & - & & -0.24 & 0.78 \\
\hline Low income & -0.84 & 0.43 & 0.58 & 1.78 & 2.01 & 7.49 & 0.33 & 1.38 & - & & 1.40 & 4.06 \\
\hline \multicolumn{13}{|l|}{ Flourishing (6) } \\
\hline Education & 0.47 & 1.61 & 0.26 & 1.30 & 0.15 & 1.17 & 0.56 & 1.76 & 0.26 & 1.30 & - & \\
\hline Employer & -0.19 & 0.83 & $-\underline{0.30}$ & $\underline{0.74}$ & 0.00 & 1.00 & -0.11 & 0.90 & -0.52 & 0.59 & - & \\
\hline Occupation & 0.30 & 1.34 & 0.34 & 1.40 & -0.07 & 0.93 & $\underline{0.47}$ & $\underline{1.60}$ & 0.28 & 1.32 & - & \\
\hline Income source & -0.04 & 0.96 & 0.16 & 1.17 & 0.19 & 1.21 & $-\underline{0.45}$ & $\underline{0.64}$ & 0.24 & 1.28 & - & \\
\hline Low income & -2.24 & 0.11 & -0.82 & 0.44 & 0.61 & 1.85 & -1.07 & 0.34 & -1.40 & 0.25 & - & \\
\hline
\end{tabular}

Participants $(n=309)$ were excluded from this analysis due to missing data. Odds ratios are presented in italics. Significant effects $(p<0.05)$ marked in bold and underlined $(p<0.10)$. Education is coded $1=$ university degree and $0=$ other. Employer is coded $1=$ has employees and $0=$ works alone. Occupation is coded $1=$ high-skilled and $0=$ other. Income source is coded $1=$ income from self-employment is a main source of household income and $0=$ other. Low income are coded $1=$ yes and $0=$ no

mean levels of variables associated with profile membership. Below, we present a detailed description of the results for the six profiles. 


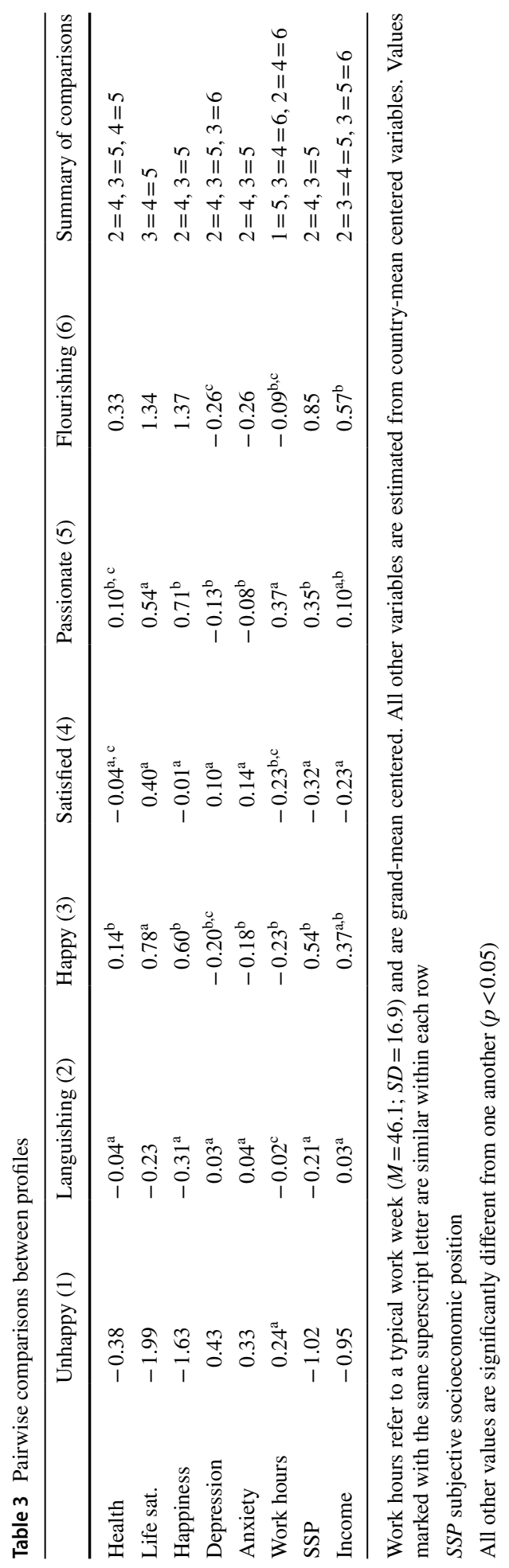




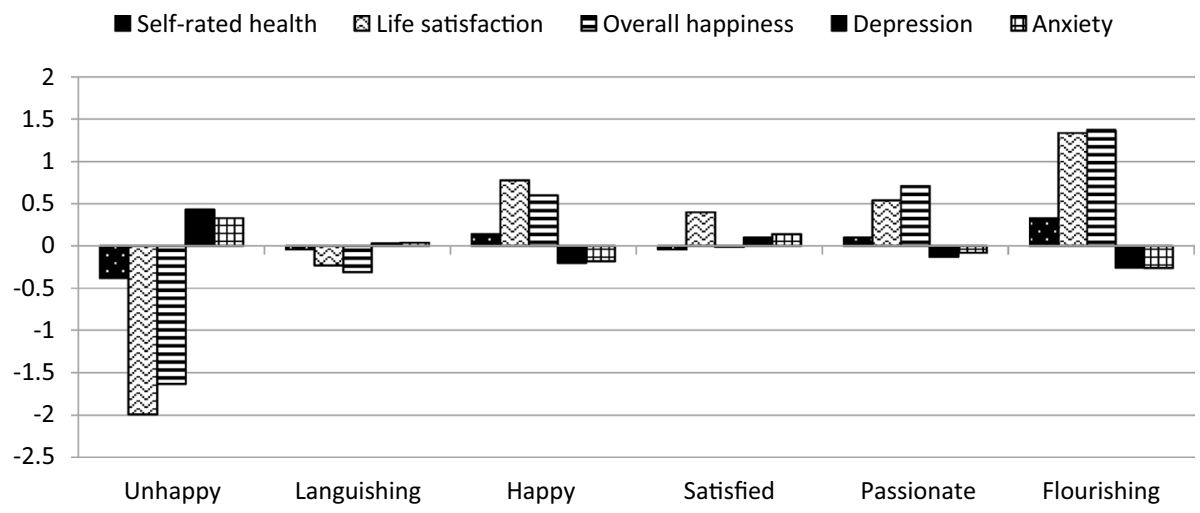

Fig. 2 Health-related characteristics associated with profile membership. Note Variables are country-mean centered

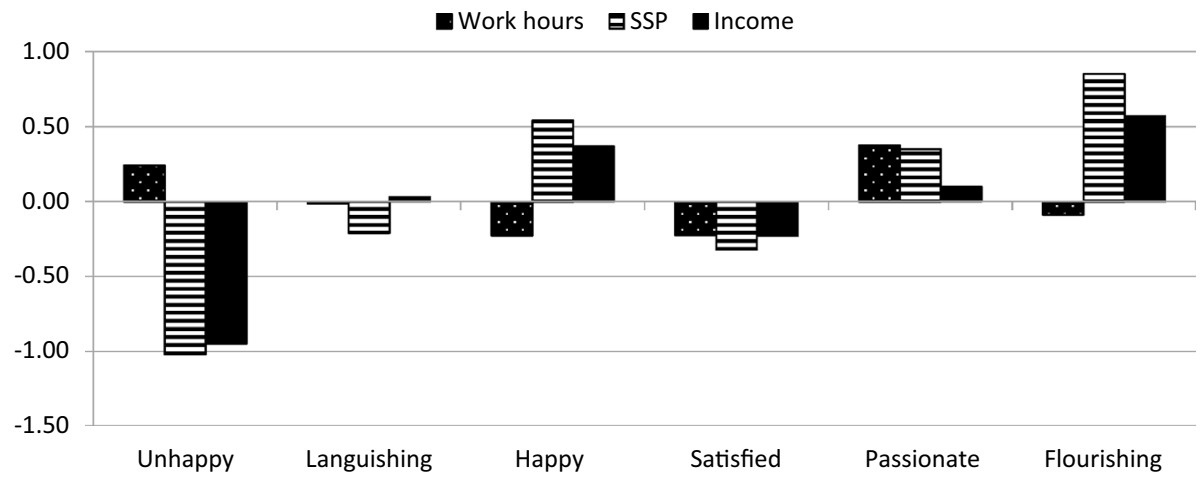

Fig. 3 Work related characteristics associated with profile membership. Note SSP subjective socioeconomic position. Work hours are grand-mean centered. SSP and income are estimated from country-mean centered variables

\subsection{The Unhappy Profile}

The Unhappy profile contained $15.2 \%$ of the sample and included workers characterized by very low well-being levels, with satisfaction scores lower than two standard deviations below the mean and eudaimonic well-being scores lower than one standard deviation below the mean. Even though the average scores for all indicators were very low, they also varied quite a lot within the Unhappy profile. Members of this profile reported significantly lower self-rated health, life satisfaction, and overall happiness than members of all other profiles. They also reported significantly higher levels of depression and anxiety than all other groups. Moreover, the Unhappy profile members had the lowest income level and were significantly more likely to consider their income as insufficient in comparison to members of all other profiles. They also reported a very low subjective socioeconomic position. Finally, members of the Unhappy profile worked longer hours than all other groups apart from the Passionate group. 


\subsection{The Languishing Profile}

The Languishing profile contained $34.2 \%$ of the sample and, thus, it represented the largest group of participants. It included individuals characterized by slightly lower than the mean levels of well-being. Members of the Languishing profile reported significantly lower life satisfaction than members of other profiles (apart from the Unhappy profile). However, their levels of self-rated health, overall happiness, depression and anxiety were similar to those of the Satisfied profile members, higher than those of the Unhappy profile members, and lower than those of the Happy, Passionate, and Flourishing profiles members. Individuals in the Languishing profile were more likely to be employers than the Happy profile members and possibly also the Flourishing profile members $(p=0.058)$. They were also more likely to consider their income as insufficient in comparison to the Happy and Flourishing profiles members, even though their income level was not significantly different from the income of the Happy profile members. Their subjective socioeconomic position was similar to the one of the Satisfied profile members and significantly lower than the one of the Happy, Passionate, and Flourishing profiles members. Lastly, they worked an average number of hours, significantly higher than the Happy profile members, but lower than the Unhappy and Passionate profile members.

\subsection{The Happy Profile}

The Happy profile contained $22.9 \%$ of the participants and was characterized by above average levels of job satisfaction, interest, stress resistance, and meaning, as well as over one standard deviation above average levels of work-life balance satisfaction and autonomy. This was also the most internally homogenous group. Its members reported above average levels of self-rated health and overall happiness, which were similar to those of the Passionate profile members, significantly higher than those of the Satisfied profile members, and significantly lower than those of the Flourishing profile members. The life satisfaction level of the Happy profile members was also significantly lower from the one of the Flourishing profile members, and no different from those of the Satisfied and Passionate profile members. Their depression levels did not differ from those of the Passionate and the Flourishing profiles members, and was significantly lower than those of the other profiles members. Their anxiety level was significantly higher than the one of the Flourishing profile members and did not differ from the one of the Passionate profile members. The members of the Happy profile were significantly more likely to hold a high-skilled occupation than members of the Unhappy, Languishing, Satisfied, and possibly also Passionate profiles $(p=0.076)$. The income level of the members of this profile was high and did not differ from the income level of the Passionate and the Flourishing profiles members. Thus, members of the Happy profile were significantly less likely to consider their income as insufficient than members of other profiles apart from the Flourishing profile. They also reported high subjective socioeconomic position, no different from members of the Passionate profile, but significantly lower than members of the Flourishing profile. In terms of work hours, members of the Happy profile worked slightly less than the sample average, similar to the member of the Satisfied and Flourishing profiles. 


\subsection{The Satisfied Profile}

The Satisfied profile contained $6.3 \%$ of the sample and, thus, it represented the smallest group of participants. Members of this profile reported about two standard deviations above average levels of job satisfaction and work-life balance, but only around average levels of eudaimonic well-being indicators. Their satisfaction levels were rather similar, yet their levels of interest, stress resistance, meaning, and control varied more within the group. Their reported around average levels of self-rated health, overall happiness, depression, and anxiety, which were no different from those of the Languishing profile members. However, their life satisfaction scores were above average and significantly lower only from those of the Flourishing profile members. The Satisfied profile members were significantly more likely to have self-employment as their main source of income in comparison to the members of all other profiles ( $p=0.086$ in comparison to the Unhappy profile and $p=0.078$ in comparison to the Flourishing profile). Their income level was significantly higher than the one of the Unhappy profile and significantly lower than the one of the Flourishing profile. However, they were more likely to find their income insufficient when compared to members of the Happy and Flourishing profiles. They also reported lower than the average subjective socioeconomic position, similar to the one of the Languishing profile members. Finally, their work hours were close to average and not significantly different from those of the Languishing, Happy, and Flourishing profiles members.

\subsection{The Passionate Profile}

The Passionate profile contained $11.8 \%$ of the self-employed. Members of this profile reported around average levels of job satisfaction, stress resistance, and control, yet over one standard deviation higher than average levels of interest and meaning as well as one standard deviation below average levels of work-life balance satisfaction. Their self-rated health, life satisfaction, and overall happiness levels were above average and similar to those of the Happy profile members. Their depression and anxiety levels were below the average and also similar to those of the Happy profile members. Members of the Passionate profile were more likely to be employers than members of the Unhappy $(p=0.078)$, Happy, Satisfied ( $p=0.099)$, and Flourishing profiles. Their income level was around average and significantly higher only from the one of the Unhappy profile members, yet they were significantly more likely to consider their income as insufficient when compared to the Languishing, Happy, and Flourishing profiles members. The Passionate profile members reported above average socioeconomic position, similar to the one of the Happy profile members. As expected due to their low work-life balance scores, the passionate group worked the longest hours, significantly longer than all groups apart from the members of the Unhappy profile.

\subsection{The Flourishing Profile}

The Flourishing profile contained $9.6 \%$ of the self-employed characterized by the highest levels of all satisfaction and well-being indicators. Thus, members of this profile also reported the highest levels of self-rated health, life satisfaction, and overall happiness. Moreover, their anxiety levels were the lowest and their depression levels were also below average and similar to the Happy profile members. The Flourishing profile members were 
more likely to hold a university degree when compared to the Unhappy and Satisfied profiles members, and were possibly also more likely to have a high-skilled occupation than the Satisfied profile members $(p=0.087)$. Their income level was above average, but similar to the one of the Happy and Passionate profile members. Yet, they were less likely to consider their income insufficient when compared to all other groups apart from the Happy profile members. Importantly, they also reported the highest subjective socioeconomic position. Finally, they worked around average number of hours, not different from members of the Languishing, Happy, and Satisfied profile members.

\section{Discussion}

The current paper provides new and unique evidence regarding the well-being of selfemployed workers due to its three main contributions: (a) it uses a person-centered approach to establish the existence of subpopulations within the group of self-employed individuals across European countries, (b) it applies a broad conceptualization of wellbeing differentiating between indicators of hedonic and eudaimonic well-being, and (c) it describes in detail the differences in well-being of the self-employed using a variety of demographic, work-related and health-related variables.

\subsection{Diversity in Well-Being Profiles Among the Self-Employed}

The results of this study clearly show that self-employed individuals are not a homogenous group when it comes to well-being. In the European context, we were able to distinguish six different well-being profiles. We would like to highlight three important findings regarding the unique composition of the well-being indicators among the self-employed.

First, surprisingly as much as $15 \%$ of the self-employed individuals were classified into the Unhappy profile, even though the self-employed were shown to have higher well-being on average than employees (e.g., Stephan and Roesler 2010). From a public health perspective, this large percentage is alarming, as these individuals seem to experience elevated levels of depression and anxiety, and suffer from low health. It may be that these individuals are less suited to be successfully self-employed, that they underwent a particularly stressful event at the time of the study, or that they are soon to quit their self-employment due to their low levels of well-being and health contributing to exit motivations (Hsu et al. 2016). Self-employed may also be particularly strongly affected by recent financial crises, such as the recession of 2008, which was associated with increasing mental health problems (Barr et al. 2015). However, a study on entrepreneurial exit revealed that entrepreneurs who changed from being an entrepreneur to be in paid employment had gained an advantage in terms of earnings only if they moved from a high-performing venture (Luzzi and Sasson 2016). Thus, simply exiting the self-employment may not be a valid solution for individuals in the Unhappy profile. It is therefore vital to further explore the reasons why these self-employed experience low well-being levels, and study possible interventions that may alleviate these symptoms.

Second, we found that around $10 \%$ of the self-employed in European population were flourishing, i.e., experiencing high levels of both hedonic and eudaimonic well-being, as well as high life satisfaction, happiness and self-rated health. Interestingly, individuals in this profile reported working only an average amount of hours and experiencing high 
work-life balance. More research targeting this group of self-employed could help better understand the reasons for their success e.g., how they move through business cycles, how they prioritize work, and how they cope with challenges and setbacks.

Third, we have found an interesting within-profile variety in levels of well-being indicators. Specifically, we identified two profiles with reverse levels of hedonic and eudaimonic well-being indicators. Individuals in the Satisfied profile reported high job and work-life balance satisfaction, yet only average levels on eudaimonic well-being indicators. Interestingly, their overall health and happiness levels were average, regardless of their high satisfaction. On the other hand, individuals in the Passionate profile reported average and low levels of satisfaction, yet their interest and meaning scores were well above average. Regardless of the low work-life balance and average job satisfaction, their overall happiness was quite high, and depression and anxiety scores below the average. Thus, the findings suggest that positive evaluations of work may not be enough for positive health outcomes to occur. High levels of eudaimonic well-being indicators seem necessary for a healthy self-employed individual.

In sum, these results highlight the need to study well-being as a multidimensional concept. The six profiles of well-being provide a rich ground for further theory development in both well-being and self-employment research.

\subsection{Understanding the Well-Being Profiles}

To better understand who (and why) seems to develop a certain well-being profile, we would also like to highlight some important covariates associated with well-being of the self-employed.

In terms of work hours, it seems that the self-employed may be able to cope with long working hours when they find their work highly interesting and meaningful, as individuals in the Passionate profile. This is an important finding since long work hours seem unavoidable for business owners (Cardon and Patel 2015; Wincent et al. 2008). Entrepreneurial passion manifests itself in working intensely (Cardon et al. 2009), and a recent study found that self-employed who work intensely felt more passionate the next week rather than the reverse (Gielnik et al. 2015). However, the caveat for working long hours was reported in below average work-life balance satisfaction in the present study. Thus, even though working many hours may further develop entrepreneurial passion, this style of work may not be sustainable due to known negative effects of long work hours on health and well-being (Virtanen et al. 2009). Further longitudinal studies are needed to better understand how passionate entrepreneurial activity affects health in the long run.

The results revealed that health variables relate mainly to the eudaimonic indicators of well-being, as they were significantly higher in profiles with above average levels of interest, stress resistance, meaning, and autonomy. This follows the direction pointed out in previous studies, that eudaimonic well-being indicators are better predictors of mental health than hedonic indicators (Huppert and So 2013). The unique role of eudaimonic well-being indicators may also, at least to some extent, explain the mixed results regarding the self-employed having better or worse health than the organizationally employed individuals (Parslow et al. 2004). As self-rated health and mental health have been shown to relate to work attendance, performance and business success, it is likely that even small improvements in the health status will make large contributions to a self-employed individual's energy, willpower, and psychological strength (Cocker et al. 2013; Fernet et al. 
2016; Gorgievski et al. 2010). Thus, interventions aiming at strengthening the eudaimonic well-being of the self-employed may be a good way to also improve their health.

In terms of the socioeconomic position, there seems to be a tendency towards a gradient, or systematic variation, in education and income levels across the different wellbeing profiles. With the exception of the Satisfied profile, all individuals who reported a high socioeconomic position and sufficient income were more likely to belong to profiles with above average levels of well-being, indicating that socioeconomic position may be an important resource for the self-employed. Public health studies showed that childhood socioeconomic position, occupational prestige, and self-rated socioeconomic position have strong positive health effects (Christ et al. 2012; Mckenzie et al. 2011; Miething 2013) and positive life satisfaction effects (Niedzwiedz et al. 2015). It also seems that socioeconomic position is tightly linked to income among the self-employed. This suggests that among the population of self-employed, there are similar socioeconomic differences in well-being as among employees (Marmot and Wilkinson 2005). Thus, future research needs to consider income and socioeconomic position as relevant resources for well-being of the self-employed.

In sum, the findings of this study point out that passion, as represented by intense work and finding one's activity highly interesting and meaningful, may play a unique role in developing and sustaining good health and high well-being levels among the selfemployed. Moreover, the results suggest that socioeconomic differences play an important role in determining entrepreneurs' well-being. Thus, these differences should not be overlooked when comparing individuals both within the group of the self-employed, as well as between the groups of the self-employed and the organizationally-employed.

\subsection{Limitations}

When interpreting the findings of this study, one needs to consider several issues that may limit our conclusions. In this paper, we combined the self-employed, business owners, and entrepreneurs. Thus, our sample includes people working for their own account and risk, as well as those helped by employees or unpaid family members (Stephan and Roesler 2010). Future research may further distinguish possible differences in wellbeing within more specific categories of self-employed individuals.

Another limitation is related to the aim of the paper to study the heterogeneity of the self-employed across European countries. While we country-centered all profile indicators, future research could benefit from conducting in-depth comparisons among countries, taking into consideration the different economic situation and governmental policies related to self-employment, welfare, and well-being in each of the countries. For example, there is a growing literature on the effects of recession on employees' wellbeing (Ogbonnaya et al. 2019), which could be extended to the self-employed. In addition, more factors than the ones studied here could be relevant to even better understand the heterogeneity of well-being of the self-employed, for instance startup motives, business sectors, and personality traits.

The findings of this study are also limited by the cross-sectional character of the data. One drawback of such study design is that we cannot make any causal inferences whether a specific covariate represents an antecedent or outcome of a profile membership. Thus, this study represents the starting point for designing a longitudinal study that will test, for instance, how profile membership relates to health outcomes over time. 
Another drawback of the cross-sectional data is that we cannot make a statement about the stability of profile memberships. It may be that some individuals change profile membership during specific times of the entrepreneurial cycle. Here, latent transition analyses will be appropriate to study changes in profile membership over time (Bujacz et al. 2018).

Finally, we did not find significantly more men/women or younger/older self-employed in any of the identified profiles. Yet, this does not mean that gender or age difference do not play an important role in determining one's well-being profile. It is plausible that wellbeing profiles may be quite different within the population of women entrepreneurs. In the future, it will be crucial to test whether the six well-being profiles can also be found (and at what prevalence) in a women-dominated sample of self-employed individuals.

Acknowledgements Open access funding provided by Karolinska Institute.

Open Access This article is distributed under the terms of the Creative Commons Attribution 4.0 International License (http://creativecommons.org/licenses/by/4.0/), which permits unrestricted use, distribution, and reproduction in any medium, provided you give appropriate credit to the original author(s) and the source, provide a link to the Creative Commons license, and indicate if changes were made.

\section{References}

Akerstedt, T., Knutsson, A., Westerholm, P., Theorell, T., Alfredsson, L., \& Kecklund, G. (2002). Sleep disturbances, work stress and work hours: A cross-sectional study. Journal of Psychosomatic Research, 53(3), 741-748.

Alesina, A., Tella, R. D., \& MacCulloch, R. (2001). Inequality and happiness: Are Europeans and Americans different? (NBER Working Paper No. 8198). Cambridge, MA. http://www.nber.org/ papers/w8198.pdf. Accessed 13 Dec 2017.

Andersson, P. (2008). Happiness and health: Well-being among the self-employed. The Journal of Socio-Economics, 37(1), 213-236. https://doi.org/10.1016/j.socec.2007.03.003.

Asparouhov, T., \& Muthén, B. (2014). Auxiliary variables in mixture modeling: Three-step approaches using Mplus. Structural Equation Modeling: A Multidisciplinary Journal, 21(3), 329-341. https:// doi.org/10.1080/10705511.2014.915181.

Bakk, Z., \& Vermunt, J. K. (2016). Robustness of stepwise latent class modeling with continuous distal outcomes. Structural Equation Modeling: A Multidisciplinary Journal, 23(1), 20-31. https://doi. org/10.1080/10705511.2014.955104.

Barlow, D. H. (2000). Unraveling the mysteries of anxiety and its disorders from the perspective of emotion theory. The American Psychologist, 55(11), 1247-1263.

Baron, R. A., Franklin, R. J., \& Hmieleski, K. M. (2016). Why entrepreneurs often experience low, not high, levels of stress: The joint effects of selection and psychological capital. Journal of Management, 42(3), 742-768. https://doi.org/10.1177/0149206313495411.

Barr, B., Kinderman, P., \& Whitehead, M. (2015). Trends in mental health inequalities in England during a period of recession, austerity and welfare reform 2004 to 2013. Social Science and Medicine, 147, 324-331. https://doi.org/10.1016/j.socscimed.2015.11.009.

Benavides, F. G. (2000). How do types of employment relate to health indicators? Findings from the Second European Survey on Working Conditions. Journal of Epidemiology and Community Health, 54(7), 494-501. https://doi.org/10.1136/jech.54.7.494.

Benz, M., \& Frey, B. S. (2008). Being independent is a great thing: Subjective evaluations of self-employment and hierarchy. Economica, 75(298), 362-383. https://doi.org/10.111 1/j.1468-0335.2007.00594.x.

Bergman, L. R., Magnusson, D., \& El-Khouri, B. M. (2003). Studying individual development in an interindividual context. A person-oriented approach. Mahwah, NJ: Lawrence Erlbaum Associates.

Bhullar, N., Hine, D. W., \& Phillips, W. J. (2014). Profiles of psychological well-being in a sample of Australian university students. International Journal of Psychology, 49(4), 288-294. https://doi. org/10.1002/ijop.12022. 
Binder, M., \& Coad, A. (2013). Life satisfaction and self-employment: A matching approach. Small Business Economics, 40(4), 1009-1033. https://doi.org/10.1007/s11187-011-9413-9.

Bradley, D. E., \& Roberts, J. A. (2004). Self-employment and job satisfaction: Investigating the role of self-efficacy, depression, and seniority. Journal of Small Business Management, 42(1), 37-58. https ://doi.org/10.1111/j.1540-627X.2004.00096.x.

Bujacz, A., Bernhard-Oettel, C., Rigotti, T., Magnusson Hanson, L., \& Lindfors, P. (2018). Psychosocial working conditions among high-skilled workers: A latent transition analysis. Journal of Occupational Health Psychology, 23(2), 223-236. https://doi.org/10.1037/ocp0000087.

Bujacz, A., Vitters $\emptyset$, J., Huta, V., \& Kaczmarek, L. D. (2014). Measuring hedonia and eudaimonia as motives for activities: Cross-national investigation through traditional and Bayesian structural equation modeling. Frontiers in Psychology, 5(September), 1-10. https://doi.org/10.3389/fpsyg .2014 .00984 .

Cardon, M. S., \& Patel, P. C. (2015). Is stress worth it? Stress-related health and wealth trade-offs for entrepreneurs. Applied Psychology, 64(2), 379-420. https://doi.org/10.1111/apps.12021.

Cardon, M. S., Wincent, J., Singh, J., \& Drnovsek, M. (2009). The nature and experience of entrepreneurial passion. Academy of Management Review, 34(3), 511-532. https://doi.org/10.5465/AMR.2009.40633 190.

Carree, M. A., \& Verheul, I. (2012). What makes entrepreneurs happy? Determinants of satisfaction among founders. Journal of Happiness Studies, 13(2), 371-387. https://doi.org/10.1007/s10902-011-9269-3.

Chevalier, S., Fouquereau, E., Gillet, N., \& Bosselut, G. (2018). Unraveling the perceived reasons underlying entrepreneurs' retirement decisions: A person-centered perspective. Journal of Small Business Management, 56(3), 513-528. https://doi.org/10.1111/jsbm.12312.

Christ, S. L., Fleming, L. E., Lee, D. J., Muntaner, C., Muennig, P. A., \& Caban-Martinez, A. J. (2012). The effects of a psychosocial dimension of socioeconomic position on survival: Occupational prestige and mortality among US working adults. Sociology of Health \& Illness, 34(7), 1103-1117. https://doi.org/ 10.1111/j.1467-9566.2012.01456.x.

Clark, A. E., Frijters, P., \& Shields, M. A. (2008). Relative income, happiness, and utility: An explanation for the easterlin paradox and other puzzles. Journal of Economic Literature, 46(1), 95-144. https://doi. org/10.1257/jel.46.1.95.

Cocker, F., Martin, A., Scott, J., Venn, A., \& Sanderson, K. (2013). Psychological distress, related work attendance, and productivity loss in small-to-medium enterprise owner/managers. International Journal of Environmental Research and Public Health, 10(10), 5062-5082. https://doi.org/10.3390/ijerp h10105062.

Collins, L. M., \& Lanza, S. T. (2010). Latent class and latent transition analysis with applications in the social, behavioral and health sciences. Hoboken: Wiley.

Deci, E. L., \& Ryan, R. M. (2000). The "What" and "Why" of goal pursuits: Human needs and the selfdetermination of behavior. Psychological Inquiry, 11(4), 227-268. https://doi.org/10.1207/S1532 7965PLI1104_01.

Diener, E., Emmons, R. A., Larsen, R. J., \& Griffin, S. (1985). The satisfaction with life scale. Journal of Personality Assessment, 49(1), 71-75. https://doi.org/10.1207/s15327752jpa4901_13.

Eurofound. (2014). Occupational profiles in working conditions: Identification of groups with multiple disadvantages. Dublin.

European Social Survey. (2012). Data Round 6.

Ezzedeen, S. R., \& Zikic, J. (2017). Finding balance amid boundarylessness: An interpretive study of entrepreneurial work-life balance and boundary management. Journal of Family Issues, 38(11), 15461576. https://doi.org/10.1177/0192513X15600731.

Fernet, C., Torrès, O., Austin, S., \& St-Pierre, J. (2016). The psychological costs of owning and managing an SME: Linking job stressors, occupational loneliness, entrepreneurial orientation, and burnout. Burnout Research, 3(2), 45-53. https://doi.org/10.1016/j.burn.2016.03.002.

Gielnik, M. M., Spitzmuller, M., Schmitt, A., Klemann, D. K., \& Frese, M. (2015). "I put in effort, therefore I am passionate": Investigating the path from effort to passion in entrepreneurship. Academy of Management Journal, 58(4), 1012-1031. https://doi.org/10.5465/amj.2011.0727.

Gorgievski, M. J., Antonio Moriano, J., \& Bakker, A. B. (2014). Relating work engagement and workaholism to entrepreneurial performance. Journal of Managerial Psychology, 29(2), 106-121. https:// doi.org/10.1108/JMP-06-2012-0169.

Gorgievski, M. J., Bakker, A. B., Schaufeli, W. B., van der Veen, H. B., \& Giesen, C. W. M. (2010). Financial problems and psychological distress: Investigating reciprocal effects among business owners. Journal of Occupational and Organizational Psychology, 83(2), 513-530. https://doi.org/10.1348/09631 7909 X434032. 
Heilala, C., Kalland, M., Komulainen, E., Solovieva, S., \& Santavirta, N. (2014). Effects of evacuation in late adulthood: Analyzing psychosocial well-being in three cluster groups of Finnish evacuees and nonevacuees. Aging \& Mental Health, 18(7), 869-878. https://doi.org/10.1080/13607863.2014.896864.

Hilbrecht, M., \& Lero, D. S. (2014). Self-employment and family life: Constructing work-life balance when you're 'always on'. Community, Work \& Family, 17(1), 20-42. https://doi.org/10.1080/13668 803.2013.862214.

Hsu, D. K., Wiklund, J., Anderson, S. E., \& Coffey, B. S. (2016). Entrepreneurial exit intentions and the business-family interface. Journal of Business Venturing, 31(6), 613-627. https://doi.org/10.1016/j. jbusvent.2016.08.001.

Huppert, F. A., \& So, T. T. C. (2013). Flourishing across Europe: Application of a new conceptual framework for defining well-being. Social Indicators Research, 110(3), 837-861. https://doi.org/10.1007/ s11205-011-9966-7.

Huta, V., \& Ryan, R. M. (2010). Pursuing pleasure or virtue: The differential and overlapping well-being benefits of hedonic and eudaimonic motives. Journal of Happiness Studies, 11, 735-762. https://doi. org/10.1007/s10902-009-9171-4.

Huta, V., \& Waterman, A. S. (2014). Eudaimonia and its distinction from hedonia: Developing a classification and terminology for understanding conceptual and operational definitions. Journal of Happiness Studies, 15(6), 1425-1456. https://doi.org/10.1007/s10902-013-9485-0.

Idler, E. L., \& Benyamini, Y. (1997). Self-rated health and mortality: A review of twenty-seven community studies. Journal of Health and Social Behavior, 38(1), 21-37.

Insel, T. R., \& Charney, D. S. (2003). Research on major depression: Strategies and priorities. JAMA, 289(23), 3167-3168. https://doi.org/10.1001/jama.289.23.3167.

Johansson Sevä, I., Vinberg, S., Nordenmark, M., \& Strandh, M. (2016). Subjective well-being among the self-employed in Europe: Macroeconomy, gender and immigrant status. Small Business Economics, 46(2), 239-253. https://doi.org/10.1007/s11187-015-9682-9.

Kahneman, D. (2000). Experienced utility and objective happiness: A moment-based approach. In D. Kahneman \& A. Tversky (Eds.), Choices, values and frames (pp. 673-692). New York: Cambridge University Press and the Russell Sage Foundation.

Kahneman, D., \& Deaton, A. (2010). High income improves evaluation of life but not emotional wellbeing. Proceedings of the National Academy of Sciences of the United States of America, 107(38), 16489-16493. https://doi.org/10.1073/pnas.1011492107.

Kahneman, D., Krueger, A. B., Schkade, D., Schwarz, N., \& Stone, A. A. (2006). Would you be happier if you were richer? A focusing illusion. Science, 312(5782), 1908-1910. https://doi.org/10.1126/ science. 1129688.

Kashdan, T. B., Biswas-Diener, R., \& King, L. A. (2008). Reconsidering happiness: The costs of distinguishing between hedonics and eudaimonia. The Journal of Positive Psychology, 3(4), 219-233. https://doi.org/10.1080/17439760802303044.

Kass, R. R. E., \& Raftery, A. E. A. (1995). Bayes factors. Journal of the American Statistical Association, 90(430), 773-795.

Lange, T. (2012). Job satisfaction and self-employment: Autonomy or personality? Small Business Economics, 38(2), 165-177. https://doi.org/10.1007/s11187-009-9249-8.

Luzzi, A., \& Sasson, A. (2016). Individual entrepreneurial exit and earnings in subsequent paid employment. Entrepreneurship Theory and Practice, 40(2), 401-420. https://doi.org/10.1111/etap.12225.

Marmot, M., \& Wilkinson, R. (2005). Social determinants of health. Oxford: Oxford University Press.

Marsh, H. W., Lüdtke, O., Trautwein, U., \& Morin, A. J. S. (2009). Classical latent profile analysis of academic self-concept dimensions: Synergy of person- and variable-centered approaches to theoretical models of self-concept. Structural Equation Modeling: A Multidisciplinary Journal, 16(2), 191-225. https://doi.org/10.1080/10705510902751010.

Mckenzie, S. K., Carter, K. N., Blakely, T., \& Ivory, V. (2011). Effects of childhood socioeconomic position on subjective health and health behaviours in adulthood: How much is mediated by adult socioeconomic position? BMC Public Health, 11(1), 269. https://doi.org/10.1186/1471-2458-11-269.

Meyer, J. P., \& Morin, A. J. S. (2016). A person-centered approach to commitment research: Theory, research, and methodology. Journal of Organizational Behavior, 37(4), 584-612. https://doi. org/10.1002/job.2085.

Miething, A. (2013). The relevance of objective and subjective social position for self-rated health: A combined approach for the Swedish context. Social Indicators Research, 111(1), 161-173. https:// doi.org/10.1007/s11205-011-9988-1.

Morin, A. J. S. (2016). Person-centered research strategies in commitment research. In J. P. Meyer (Ed.), The handbook of employee commitment (pp. 490-508). Cheltenham: Edward Elgar Publishing. 
Morin, A. J. S., Bujacz, A., \& Gagné, M. (2018). Person-centered methodologies in the organizational sciences: Introduction to the feature topic. Organizational Research Methods, 21(4), 803-813. https ://doi.org/10.1177/1094428118773856.

Myrie, J., \& Daly, K. (2009). The use of boundaries by self-employed, home-based workers to manage work and family: A qualitative study in Canada. Journal of Family and Economic Issues, 30(4), 386-398. https://doi.org/10.1007/s10834-009-9166-7.

Niedzwiedz, C. L., Pell, J. P., \& Mitchell, R. (2015). The relationship between financial distress and life-course socioeconomic inequalities in well-being: Cross-national analysis of European welfare states. American Journal of Public Health, 105(10), 2090-2098. https://doi.org/10.2105/ AJPH.2015.302722.

Ogbonnaya, C., Gahan, P., \& Eib, C. (2019). Recessionary changes at work and employee well-being: The protective roles of national and workplace institutions. European Journal of Industrial Relations. https://doi.org/10.1177/0959680119830885.

Parasuraman, S., \& Simmers, C. A. (2001). Type of employment, work-family conflict and well-being: A comparative study. Journal of Organizational Behavior, 22(5), 551-568. https://doi.org/10.1002/ job.102.

Parslow, R. A., Jorm, A. F., Christensen, H., Rodgers, B., Strazdins, L., \& D’Souza, R. M. (2004). The associations between work stress and mental health: A comparison of organizationally employed and selfemployed workers. Work \& Stress, 18(3), 231-244. https://doi.org/10.1080/14749730412331318649.

Rauch, A., \& Frese, M. (2000). Psychological approaches to entrepreneurial success: A general model and an overview of findings. In C. L. Cooper \& I. T. Robertson (Eds.), International review of industrial and organizational psychology (pp. 101-142). Chichester: Wiley.

Rietveld, C. A., van Kippersluis, H., \& Thurik, A. R. (2015). Self-employment and health: Barriers or benefits? Health Economics, 24(10), 1302-1313. https://doi.org/10.1002/hec.3087.

Ryff, C. D. (2013). Psychological well-being revisited: Advances in the science and practice of eudaimonia. Psychotherapy and Psychosomatics, 83(1), 10-28. https://doi.org/10.1159/000353263.

Schonfeld, I. S., \& Mazzola, J. J. (2015). A qualitative study of stress in individuals self-employed in solo businesses. Journal of Occupational Health Psychology, 20(4), 501-513. https://doi.org/10.1037/ a0038804.

Schueller, S. M., \& Seligman, M. E. P. (2010). Pursuit of pleasure, engagement, and meaning: Relationships to subjective and objective measures of well-being. The Journal of Positive Psychology, 5(4), 253-263. https://doi.org/10.1080/17439761003794130.

Smith, B. W., Tooley, E. M., Christopher, P. J., \& Kay, V. S. (2010). Resilience as the ability to bounce back from stress: A neglected personal resource? The Journal of Positive Psychology, 5(3), 166-176. https:// doi.org/10.1080/17439760.2010.482186.

Sonnentag, S., \& Bayer, U.-V. (2005). Switching off mentally: Predictors and consequences of psychological detachment from work during off-job time. Journal of Occupational Health Psychology, 10(4), 393-414. https://doi.org/10.1037/1076-8998.10.4.393.

Spivack, A. J., McKelvie, A., \& Haynie, J. M. (2014). Habitual entrepreneurs: Possible cases of entrepreneurship addiction? Journal of Business Venturing, 29(5), 651-667. https://doi.org/10.1016/j.jbusv ent.2013.11.002.

Steger, M. F., Oishi, S., \& Kashdan, T. B. (2009). Meaning in life across the life span: Levels and correlates of meaning in life from emerging adulthood to older adulthood. The Journal of Positive Psychology, 4(1), 43-52. https://doi.org/10.1080/17439760802303127.

Stephan, U., Hart, M., Michiewicz, T., \& Drews, C.-C. (2015). Understanding motivations for entrepreneurship: A review of recent research evidence. Birmingham: Enterprise Research Centre.

Stephan, U., \& Roesler, U. (2010). Health of entrepreneurs versus employees in a national representative sample. Journal of Occupational and Organizational Psychology, 83(3), 717-738. https://doi. org/10.1348/096317909X472067.

Toivanen, S., Mellner, C., \& Vinberg, S. (2015). Self-employed persons in Sweden-mortality differentials by industrial sector and enterprise legal form: A five-year follow-up study. American Journal of Industrial Medicine, 58(1), 21-32. https://doi.org/10.1002/ajim.22387.

Uy, M. A., Foo, M.-D., \& Song, Z. (2013). Joint effects of prior start-up experience and coping strategies on entrepreneurs' psychological well-being. Journal of Business Venturing, 28(5), 583-597. https://doi. org/10.1016/j.jbusvent.2012.04.003.

Uy, M. A., Sun, S., \& Foo, M.-D. (2017). Affect spin, entrepreneurs' well-being, and venture goal progress: The moderating role of goal orientation. Journal of Business Venturing, 32(4), 443-460. https://doi. org/10.1016/j.jbusvent.2016.12.001. 
van der Zwan, P., Thurik, R., Verheul, I., \& Hessels, J. (2016). Factors influencing the entrepreneurial engagement of opportunity and necessity entrepreneurs. Eurasian Business Review, 6(3), 273-295. https://doi.org/10.1007/s40821-016-0065-1.

van Gelderen, M. (2016). Entrepreneurial autonomy and its dynamics. Applied Psychology, 65(3), 541-567. https://doi.org/10.1111/apps.12066.

Virtanen, M., Ferrie, J. E., Gimeno, D., Vahtera, J., Elovainio, M., Singh-Manoux, A., et al. (2009). Long working hours and sleep disturbances: The Whitehall II prospective cohort study. Sleep, 32(6), $737-745$.

Vitters $\emptyset$, J., \& Dahl, T. I. (2013). What's in a face? Perhaps some elements of both eudaimonic and hedonic well-being. The Journal of Positive Psychology, 8(May), 1-9. https://doi.org/10.1080/17439 760.2013.803597.

Vittersø, J., Oelmann, H. I., \& Wang, A. L. (2009a). Life satisfaction is not a balanced estimator of the good life: Evidence from reaction time measures and self-reported emotions. Journal of Happiness Studies, 10(1), 1-17. https://doi.org/10.1007/s10902-007-9058-1.

Vitters $\varnothing$, J., Overwien, P., \& Martinsen, E. (2009b). Pleasure and interest are differentially affected by replaying versus analyzing a happy life moment. The Journal of Positive Psychology, 4(1), 14-20. https://doi.org/10.1080/17439760802060602.

Wang, M., \& Hanges, P. J. (2011). Latent class procedures: Applications to organizational research. Organizational Research Methods, 14(1), 24-31. https://doi.org/10.1177/1094428110383988.

Weiss, H. M. (2002). Deconstructing job satisfaction. Human Resource Management Review, 12(2), 173194. https://doi.org/10.1016/S1053-4822(02)00045-1.

Wincent, J., Örtqvist, D., \& Drnovsek, M. (2008). The entrepreneur's role stressors and proclivity for a venture withdrawal. Scandinavian Journal of Management, 24(3), 232-246. https://doi.org/10.1016/j. scaman.2008.04.001.

Publisher's Note Springer Nature remains neutral with regard to jurisdictional claims in published maps and institutional affiliations. 